can be expertly administered. ${ }^{18}$ Ideally, as many patients as possible would be treated within 90 or 120 minutes of onset, when benefit is maximal. The time has come for proponents of thrombolysis and reformed thrombolytic contrarians to join together to improve systems of acute stroke care worldwide so that more properly evaluated, properly selected, and properly informed stroke patients can be treated with intravenous thrombolytics within three hours of onset.

JLS, CSK, and SS have served as site investigators in acute stroke clinical trials sponsored by several (15, 11 , and 17 respectively) pharmaceutical and biotechnology companies, including Genentech and Boehringer-Ingelheim; have received speaking honorariums from several $(12,5,8)$ pharmaceutical companies, including Genentech and Boehringer-Ingelheim; and have served as consultants on scientific advisory boards for several ( 7 , $1,5)$ pharmaceutical and biotechnology companies developing acute stroke treaments, including Boehringer-Ingelheim and Genentech.

1 NINDS rt-PA Stroke Group. Tissue plasminogen activator for acute ischemic stroke. N Engl J Med 1995;333:1581-7.

2 Steiner T, Bluhmki E, Kaste M, Toni D, Trouillas P, von Kummer R, et al The ECASS 3-hour cohort. Secondary analysis of ECASS data by time stratification. ECASS Study Group. European Cooperative Acute Stroke Study. Cerebrovasc Dis 1998;8:198-203.

3 Albers GW, Clark WM, Madden KP, Hamilton SA. ATLANTIS trial: results for patients treated within 3 hours of stroke onset. Alteplase Thrombolysis for Acute Noninterventional Therapy in Ischemic Stroke. Stroke 2002;33:493-6.
4 Hacke W, Brott T, Caplan L, Meier D, Fieschi C, von Kummer R, et al. Thrombolysis in acute ischemic stroke: controlled trials and clinical experience. Neurology 1999;53:S3-14.

5 Wardlaw JM, del Zoppo G, Yamaguchi T. Thrombolysis for acute ischaemic stroke. Cochrane Database Syst Rev 2000;(1):CD000213.

6 Walter SD. Number needed to treat (NNT): estimation of a mesaure of clinical benefit. Stat Med2001;20:3947-62.

7 Lees KR. Thrombolysis. Br Med Bull 2000;56:389-400.

8 Haley EC Jr, Lewandowski C, Tilley BC. Myths regarding the NINDS rt-PA Stroke Trial: setting the record straight. Ann Energ Med 1977;30:676-82.

9 Liebeskind DS, Kidwell CS, Saver JL. Empiric evidence of publication bias affecting acute stroke clinical trials. Stroke 1999;30:268.

10 Choudhry NK, Stelfox HT, Detsky AS. Relationships between authors of clinical practice guidelines and the pharmaceutical industry. JAMA 2002;287:612-7

11 Rothman KJ, Cann CI. Judging words rather than authors. Epidemiology 1997;8:223-5.

12 Smith R. Beyond conflict of interest. Transparency is the key. BMJ 1998;317:291-2.

13 Hoffman J.IV t-PA interventional therapy for acute stroke patients: negative position. Stroke Interventionalist 2002;11:6-10.

14 Weiss RA, Jaffe HW. Duesberg, HIV and AIDS. Nature 1990;345:659-60.

15 Katzan IL, Furlan AJ, Lloyd LE, Frank JI, Harper DL, Hinchey JA, et al. Use of tissue-type plasminogen activator for acute ischemic stroke: the Cleveland area experience. JAMA 2000;283:1151-8.

16 Morgenstern LB, Staub L, Chan W, Wein TH, Bartholomew LK, King M, et al. Improving delivery of acute stroke therapy: The TLL Temple Foundation Stroke Project. Stroke 2002;33:160-6.

17 Merino JG, Silver B, Wong E, Foell B, Demaerschalk B, Tamayo A, et al. Extending tissue plasminogen activator use to community and rural stroke patients. Stroke 2002;33:141-6.

18 Alberts MJ, Hademenos G, Latchaw RE, Jagoda A, Marler JR, Mayber MR, et al.: Recommendations for the establishment of primary stroke centers. Brain Attack Coalition. JAMA 2000;283:3102-9.

\title{
Evidence base of clinical diagnosis Clinical problem solving and diagnostic decision making: selective review of the cognitive literature
}

\author{
Arthur S Elstein, Alan Schwarz
}

This article reviews our current understanding of the cognitive processes involved in diagnostic reasoning in clinical medicine. It describes and analyses the psychological processes employed in identifying and solving diagnostic problems and reviews errors and pitfalls in diagnostic reasoning in the light of two particularly influential approaches: problem solving ${ }^{1-3}$ and decision making. ${ }^{4-8}$ Problem solving research was initially aimed at describing reasoning by expert physicians, to improve instruction of medical students and house officers. Psychological decision research has been influenced from the start by statistical models of reasoning under uncertainty, and has concentrated on identifying departures from these standards.

\section{Problem solving}

Diagnosis as selecting a hypothesis

The earliest psychological formulation viewed diagnostic reasoning as a process of testing hypotheses. Solutions to difficult diagnostic problems were found by generating a limited number of hypotheses early in the diagnostic process and using them to guide subsequent collection of data. ${ }^{1}$ Each hypothesis can be used to predict what additional findings ought to be present if it were true, and the diagnostic process is a guided search for these findings. Experienced physicians form hypotheses and their diagnostic plan rapidly, and the quality of their hypotheses is higher than that of novices. Novices

\section{Summary points}

Problem solving and decision making are two paradigms for psychological research on clinical reasoning, each with its own assumptions and methods

The choice of strategy for diagnostic problem solving depends on the perceived difficulty of the case and on knowledge of content as well as strategy

Final conclusions should depend both on prior belief and strength of the evidence

Conclusions reached by Bayes's theorem and clinical intuition may conflict

Because of cognitive limitations, systematic biases and errors result from employing simpler rather than more complex cognitive strategies

Evidence based medicine applies decision theory to clinical diagnosis

struggle to develop a plan and some have difficulty moving beyond collection of data to considering possibilities.
This is the fourth in a series of five articles

Department of Medical Education, University of Illinois College of Medicine, Chicago, IL 60612-7309, USA

Arthur S Elstein professor

Alan Schwarz assistant professor of clinical decision making

Correspondence to: A S Elstein aelstein@uic.edu

Series editor: J A Knottnerus

BMJ 2002;324:729-32 
It is possible to collect data thoroughly but nevertheless to ignore, to misunderstand, or to misinterpret some findings, but also possible for a clinician to be too economical in collecting data and yet to interpret accurately what is available. Accuracy and thoroughness are analytically separable.

\section{Pattern recognition or categorisation}

Expertise in problem solving varies greatly between individual clinicians and is highly dependent on the clinician's mastery of the particular domain. ${ }^{9}$ This finding challenges the hypothetico-deductive model of clinical reasoning, since both successful and unsuccessful diagnosticians use hypothesis testing. It appears that diagnostic accuracy does not depend as much on strategy as on mastery of content. Further, the clinical reasoning of experts in familiar situations frequently does not involve explicit testing of hypotheses. ${ }^{3}{ }^{10-12}$ Their speed, efficiency, and accuracy suggest that they may not even use the same reasoning processes as novices. ${ }^{11}$ It is likely that experienced physicians use a hypothetico-deductive strategy only with difficult cases and that clinical reasoning is more a matter of pattern recognition or direct automatic retrieval. What are the patterns? What is retrieved? These questions signal a shift from the study of judgment to the study of the organisation and retrieval of memories.

Viewing the process of diagnosis assigning a case to a category brings some other issues into clearer view. How is a new case categorised? Two competing answers to this question have been put forward and research evidence supports both. Category assignment can be based on matching the case to a specific instance ("instance based" or "exemplar based" recognition) or to a more abstract prototype. In the former, a new case is categorised by its resemblance to memories of instances previously seen. ${ }^{31}$ This model is supported by the fact that clinical diagnosis is strongly affected by context-for example, the location of a skin rash on the body-even when the context ought to be irrelevant. ${ }^{12}$

The prototype model holds that clinical experience facilitates the construction of mental models, abstractions, or prototypes. ${ }^{213}$ Several characteristics of experts support this view-for instance, they can better identify the additional findings needed to complete a clinical picture and relate the findings to an overall concept of the case. These features suggest that better diagnosticians have constructed more diversified and abstract sets of semantic relations, a network of links between clinical features and diagnostic categories. ${ }^{14}$

The controversy about the methods used in diagnostic reasoning can be resolved by recognising that clinicians approach problems flexibly; the method they select depends upon the perceived characteristics of the problem. Easy cases can be solved by pattern recognition: difficult cases need systematic generation and testing of hypotheses. Whether a diagnostic prob-

Problem solving strategies

- Hypothesis testing

- Pattern recognition (categorisation)

- By specific instances

- By general prototypes lem is easy or difficult is a function of the knowledge and experience of the clinician.

The strategies reviewed are neither proof against error nor always consistent with statistical rules of inference. Errors that can occur in difficult cases in internal medicine include failure to generate the correct hypothesis; misperception or misreading the evidence, especially visual cues; and misinterpretations of the evidence. ${ }^{15}{ }^{16}$ Many diagnostic problems are so complex that the correct solution is not contained in the initial set of hypotheses. Restructuring and reformulating should occur as data are obtained and the clinical picture evolves. However, a clinician may quickly become psychologically committed to a particular hypothesis, making it more difficult to restructure the problem.

\section{Decision making}

\section{Diagnosis as opinion revision}

From the point of view of decision theory, reaching a diagnosis means updating opinion with imperfect information (the clinical evidence). ${ }^{8}{ }^{17}$ The standard rule for this task is Bayes's theorem. The pretest probability is either the known prevalence of the disease or the clinician's subjective impression of the probability of disease before new information is acquired. The post-test probability, the probability of disease given new information, is a function of two variables, pretest probability and the strength of the evidence, measured by a "likelihood ratio."

Bayes's theorem tells us how we should reason, but it does not claim to describe how opinions are revised. In our experience, clinicians trained in methods of evidence based medicine are more likely than untrained clinicians to use a Bayesian approach to interpreting findings. ${ }^{18}$ Nevertheless, probably only a minority of clinicians use it in daily practice and informal methods of opinion revision still predominate. Bayes's theorem directs attention to two major classes of errors in clinical reasoning: in the assessment of either pretest probability or the strength of the evidence. The psychological study of diagnostic reasoning from this viewpoint has focused on errors in both components, and on the simplifying rules or heuristics that replace more complex procedures. Consequently, this approach has become widely known as "heuristics and biases." 19

\section{Errors in estimation of probability}

Availability-People are apt to overestimate the frequency of vivid or easily recalled events and to underestimate the frequency of events that are either very ordinary or difficult to recall. Diseases or injuries that receive considerable media attention are often thought of as occurring more commonly than they actually do. This psychological principle is exemplified clinically in the overemphasis of rare conditions, because unusual cases are more memorable than routine problems.

Representativeness-Representativeness refers to estimating the probability of disease by judging how similar a case is to a diagnostic category or prototype. It can lead to overestimation of probability either by causing confusion of post-test probability with test sensitivity or by leading to neglect of base rates and implicitly considering all hypotheses equally likely. This 
Heuristics and biases

- Availability

- Representativeness

- Probability transformations

- Effect of description detail

- Conservatism

- Anchoring and adjustment

- Order effects

is an error, because if a case resembles disease $\mathrm{A}$ and disease $\mathrm{B}$ equally, and $\mathrm{A}$ is much more common than $\mathrm{B}$, then the case is more likely to be an instance of $\mathrm{A}$. Representativeness is associated with the "conjunction fallacy"-incorrectly concluding that the probability of a joint event (such as the combination of findings to form a typical clinical picture) is greater than the probability of any one of these events alone.

\section{Probability transformations}

Decision theory assumes that in psychological processing of probabilities, they are not transformed from the ordinary probability scale. Prospect theory was formulated as a descriptive account of choices involving gambling on two outcomes, ${ }^{20}$ and cumulative prospect theory extends the theory to cases with multiple outcomes. ${ }^{21}$ Both prospect theory and cumulative prospect theory propose that, in decision making, small probabilities are overweighted and large probabilities underweighted, contrary to the assumption of standard decision theory. This "compression" of the probability scale explains why the difference between $99 \%$ and $100 \%$ is psychologically much greater than the difference between, say, $60 \%$ and $61 \%{ }^{22}$

\section{Support theory}

Support theory proposes that the subjective probability of an event is inappropriately influenced by how detailed the description is. More explicit descriptions yield higher probability estimates than compact, condensed descriptions, even when the two refer to exactly the same events. Clinically, support theory predicts that a longer, more detailed case description will be assigned a higher subjective probability of the index disease than a brief abstract of the same case, even if they contain the same information about that disease. Thus, subjective assessments of events, while often necessary in clinical practice, can be affected by factors unrelated to true prevalence. ${ }^{23}$

\section{Errors in revision of probability}

In clinical case discussions, data are presented sequentially, and diagnostic probabilities are not revised as much as is implied by Bayes's theorem ${ }^{8}$; this phenomenon is called conservatism. One explanation is that diagnostic opinions are revised up or down from an initial anchor, which is either given in the problem or subjectively formed. Final opinions are sensitive to the starting point (the "anchor"), and the shift ("adjustment") from it is typically insufficient. ${ }^{4}$ Both biases will lead to collecting more information than is necessary to reach a desired level of diagnostic certainty.

It is difficult for everyday judgment to keep separate accounts of the probability of a disease and the benefits that accrue from detecting it. Probability revision errors that are systematically linked to the perceived cost of mistakes show the difficulties experienced in separating assessments of probability from values, as required by standard decision theory. There is a tendency to overestimate the probability of more serious but treatable diseases, because a clinician would hate to miss one. ${ }^{24}$

Bayes's theorem implies that clinicians given identical information should reach the same diagnostic opinion, regardless of the order in which information is presented. However, final opinions are also affected by the order of presentation of information. Information presented later in a case is given more weight than information presented earlier. ${ }^{25}$

Other errors identified in data interpretation include simplifying a diagnostic problem by interpreting findings as consistent with a single hypothesis, forgetting facts inconsistent with a favoured hypothesis, overemphasising positive findings, and discounting negative findings. From a Bayesian standpoint, these are all errors in assessing the diagnostic value of clinical evidence-that is, errors in implicit likelihood ratios.

\section{Educational implications}

Two recent innovations in medical education, problem based learning and evidence based medicine, are consistent with the educational implications of this research. Problem based learning can be understood as an effort to introduce the formulation and testing of clinical hypotheses into the preclinical curriculum. ${ }^{26}$ The theory of cognition and instruction underlying this reform is that since experienced physicians use this strategy with difficult problems, and since practically any clinical situation selected for instructional purposes will be difficult for students, it makes sense to provide opportunities for students to practise problem solving with cases graded in difficulty. The finding of case specificity showed the limits of teaching a general problem solving strategy. Expertise in problem solving can be separated from content analytically, but not in practice. This realisation shifted the emphasis towards helping students acquire a functional organisation of content with clinically usable schemas. This goal became the new rationale for problem based learning. ${ }^{27}$

Evidence based medicine is the most recent, and by most standards the most successful, effort to date to apply statistical decision theory in clinical medicine. ${ }^{18}$ It teaches Bayes's theorem, and residents and medical students quickly learn how to interpret diagnostic studies and how to use a computer based nomogram to compute post-test probabilities and to understand the output. ${ }^{28}$

\section{Conclusion}

We have selectively reviewed 30 years of psychological research on clinical diagnostic reasoning. The problem solving approach has focused on diagnosis as hypothesis testing, pattern matching, or categorisation. The errors in reasoning identified from this perspective include failure to generate the correct hypothesis; misperceiving or misreading the evidence, especially visual cues; and misinterpreting the evidence. The decision making approach views diagnosis as opinion revision 


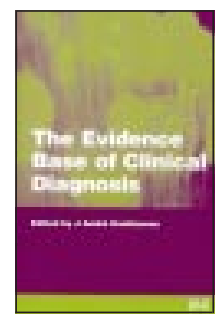

"The Evidence Base of Clinical Diagnosis," edited by J A Knottnerus, can be purchased through the BMJ Bookshop (www. bmjbookshop.com with imperfect information. Heuristics and biases in estimation and revision of probability have been the subject of intense scrutiny within this research tradition. Both research paradigms understand judgment errors as a natural consequence of limitations in our cognitive capacities and of the human tendency to adopt short cuts in reasoning.

Both approaches have focused more on the mistakes made by both experts and novices than on what they get right, possibly leading to overestimation of the frequency of the mistakes catalogued in this article. The reason for this focus seems clear enough: from the standpoint of basic research, errors tell us a great deal about fundamental cognitive processes, just as optical illusions teach us about the functioning of the visual system. From the educational standpoint, clinical instruction and training should focus more on what needs improvement than on what learners do correctly; to improve performance requires identifying errors. But, in conclusion, we emphasise, firstly, that the prevalence of these errors has not been established; secondly, we believe that expert clinical reasoning is very likely to be right in the majority of cases; and, thirdly, despite the expansion of statistically grounded decision supports, expert judgment will still be needed to apply general principles to specific cases.

Preparation of this review was supported in part by grant RO1 LM5630 from the National Library of Medicine.

Competing interests: None declared.

1 Elstein AS, Shulman LS, Sprafka SA. Medical problem solving: an analysis of clinical reasoming. Cambridge, MA: Harvard University Press, 1978.

2 Bordage G, Zacks R. The structure of medical knowledge in the Bordage $G$, Zacks R. The structure of medical knowledge in the
memories of medical students and general practitioners: categories and memories of medical students and ge
prototypes. Med Educ 1984;18:406-16.

3 Schmidt HG, Norman GR, Boshuizen HPA. A cognitive perspective on medical expertise: theory and implications. Acad Med 1990;65:611-21.

4 Kahneman D, Slovic P, Tversky A, eds. Judgment under uncertainty: heuristics and biases. New York: Cambridge University Press, 1982.
5 Sox HC Jr, Blatt MA, Higgins MC, Marton KI. Medical decision making. Stoneham, MA: Butterworths, 1988

6 Mellers BA, Schwartz A, Cooke ADJ.Judgment and decision making. Ann Reu Psychol 1998; 49:447-77.

7 Chapman GB, Sonnenberg F, eds. Decision making in health care: theory, psychology, and applications. New York: Cambridge University Press, 2000.

8 Hunink M, Glasziou P, Siegel J, Weeks J, Pliskin J, Elstein AS, et al. Decision making in health and medicine: integrating evidence and values. New York: Cambridge University Press, 2001.

9 Patel VL, Groen G. Knowledge-based solution strategies in medical reasoning. Cogn Sci 1986;10:91-116.

10 Groen GJ, Patel VL. Medical problem-solving: some questionable assumptions. Med Educ 1985;19:95-100.

11 Brooks LR, Norman GR, Allen SW. Role of specific similarity in a medical diagnostic task. J Exp Psychol Gen 1991;120:278-87.

12 Norman GR, Coblentz CL, Brooks LR, Babcock CJ. Expertise in visual diagnosis: a review of the literature. Acad Med 1992;66(suppl):S78-83.

13 Rosch E, Mervis CB. Family resemblances: studies in the internal structure of categories. Cogn Psychol 1975;7:573-605.

14 Lemieux M, Bordage G. Propositional versus structural semantic analyses of medical diagnostic thinking. Cogn Science 1992;16:185-204.

15 Kassirer JP, Kopelman RI. Learning clinical reasoning. Baltimore: Williams and Wilkins, 1991

16 Bordage G. Why did I miss the diagnosis? Some cognitive explanations and educational implications. Acad Med 1999;74(suppl):S138-42.

17 Sackett DL, Haynes RB, Guyatt GH, Tugwell P. Clinical epidemiology: a basic science for clinical medicine. 2nd ed. Boston: Little, Brown, 1991.

18 Sackett DL, Richardson WS, Rosenberg W, Haynes RB. Evidence-based medicine: how to practice and teach EBM. New York: Churchill Livingstone, 1997.

19 Elstein AS. Heuristics and biases: selected errors in clinical reasoning. Acad Med 1999;74:791-4.

20 Tversky A, Kahneman D. The framing of decisions and the psychology of choice. Science 1982;211:453-8.

21 Tversky A, Kahneman D. Advances in prospect theory: cumulative representation of uncertainty. J Risk Uncertain 1992;5:297-323.

22 Fischhoff B, Bostrom A, Quadrell M J. Risk perception and communication. Annu Rev Pub Health, 1993;4:183-203.

23 Redelmeier DA, Koehler DJ, Liberman V, Tversky A. Probability judgment in medicine: discounting unspecified probabilities. Med Decis Making 1995:15:227-30.

24 Wallsten TS. Physician and medical student bias in evaluating information. Med Decis Making 1981;1:145-64.

25 Bergus GR, Chapman GB, Gjerde C, Elstein AS. Clinical reasoning about new symptoms in the face of pre-existing disease: sources of error and order effects. Fam Med 1995;27:314-20.

26 Barrows HS. Problem-based, self-directed learning. JAMA 1983;250: 3077-80.

27 Gruppen LD. Implications of cognitive research for ambulatory care education. Acad Med 1997;72:117-20.

28 Schwartz A. Nomogram for Baves's theorem. http://araw.mede.uic.edu/ cgi-bin/testcalc.pl (accessed 28 December 2001).

\section{The $B M J$ as recreational reading}

My partners in the practice think it rather odd when I tell them I take a bundle of unread $B M / \mathrm{s}$ from the preceding three months on holiday with me, for recreational reading. Relax, they say, get away from medicine for a while. But they are wrong. Apart from the benefit that, when read, I can discard them, giving me extra room in the case for packing books to take home, I do find reading several $B M J \mathrm{~s}$ in rapid sequence very relaxing.

Looking back to childhood, I remember my elder brother returning from boarding school and sitting himself happily in an armchair with a pile of copies of the Eagle comic from the preceding school term and reading them in rapid sequence. Not for him the agonising wait for a week to see what has happened to the Mekon and Dan Dare. He could enjoy it all at one go.

It is a bit like that for me and the $B M J$. You get into a good rhythm and, for example, can follow trends in the News sections all at once, as it were. My system starts with a scan through the Editor's Choice, a steady flick through from there on, homing in on any article of particular interest. With the recent editorial policy of publishing a set of letters commenting on a particular controversy some time after the instigating paper, I can often read the comments almost at the same time as the offending piece, so it is fresh in my mind (a recent example is the editorial on cheating at medical school (12 August 2000) and the subsequent letters).

Reading the $B M J$ as a recreation means that I can spend as long as I like on any particular article and relish the lighter "magazine" articles, Minerva, and the Fillers. Certain items achieve a particular status for me-these are the ones I carefully tear out of the issue in question and preserve for further action on return to work. Choosing what is worthy of preservation will always, of course, be a very personal thing.

On my last holiday, I preserved a Minerva piece on marinating cheese; an editorial describing problems with attention deficit hyperactivity disorder; another Minerva piece on rowing and backache to show my son in law, who suffered from just such a problem; advice for health in old age; a review of Tim Albert's latest book on medical writing; a description of emergency care on aircraft flights; advice on when to use dummies in babies (Minerva again); a wonderfully succinct guide to gallstone disease; and a Filler of tips by a ship's doctor.

I recommend the exercise. Of course, I should read my copies of the $B M J$ when I receive them, and I do always return from holiday with this firm intention...

Selwyn Goodacre general practitioner, Swadlincote, Derbyshire We welcome articles up to 600 words on topics such as A memorable patient, A paper that changed my practice, My most unfortunate mistake, or any other piece conveying instruction, pathos, or humour. If possible the article should be supplied on a disk. Permission is needed from the patient or a relative if an identifiable patient is referred to. We also welcome contributions for "Endpieces," consisting of quotations of up to 80 words (but most are considerably shorter) from any source, ancient or modern, which have appealed to the reader. 